Gut, 1984, 25, 587-597

Leading article

\title{
Endoscopic management of bile duct stones; (apples and oranges)
}

The 10th birthday of endoscopic sphincterotomy recently followed closely upon the centennial of the first cholecystectomy. The $>50000$ sphincterotomies already performed are an eloquent testimony for the techniques and its pioneers. ${ }^{1}$ Acceptance has been grudging in some quarters, but few could now argue convincingly against its use - for example, in frail and elderly patients with stones retained after cholecystectomy. In general endoscopic treatment is simpler and cheaper than surgery and is preferred by patients. Rather than discuss indications for endoscopic treatment, its protagonists can argue that it is for surgeons to justify the use of an operative approach. What, if any, are the indications for surgical exploration of the duct? Such statements are provocative. Endoscopic techniques would probably not have been developed so quickly and effectively without some element of competition, but uncritical argument is not productive. The endoscopic honeymoon should give way to more sober consideration. The young bucks have proved their virility; indeed some. may now feel it threatened by the clinical burden which they have placed on their own backs. Many have learnt that there are limits to their skills and that surgeons can also do remarkable things. There is a basic obligation to work together to establish the real indications for the different methods.

Patients with symptomatic duct stones want to know the chances of success, and both the short and long term risks of endoscopic and operative treatments. The paper from Toulouse in this issue of Gut is a welcome addition to the developing literature. Unfortunately, virtually all reports deal with selected patients who are not defined in sufficient detail. The spectrum of patients referred to surgeons and endoscopists is not the same, nor should it be. Failure to appreciate this has led to many futile arguments; those who try to compare apples and oranges are destined to trip over bananas. This problem of non-comparable data will inevitably increase as indications are better defined; the hazards of surgery will appear to lessen as patients carrying the highest risk are deflected for endoscopic treatment. Figures from a single institution using both methods are of considerable interest, ${ }^{2}$ but some randomised studies are essential.

It would be much easier to detect factors which really predict outcome and therefore to define indications, if all workers in this field used similar documentation. Some of the points to be considered are discussed. (This review excludes patients with T-tube drains, for whom other methods are available.)

Factors influencing the choice of treatment

SUCCESS RATES FOR ENDOSCOPIC TREATMENT

Success rates of over $95 \%$ are reported, but these data need careful 
scrutiny. Some reports refer only to the success rate of performing a sphincterotomy (which should be close to $100 \%$ ), or only of extracting stones (which is more difficult), once sphincterotomy has been done. In most series the actual success rates for these two elements are about $95 \%$ and $90 \%$ respectively, giving an overall figure for duct clearance of some $85 \% ;^{3-8}$ this was lower when initial British experience was collected. ${ }^{9}$ Our own figures when last analysed were $96 \%$ and $93 \%$, making $87 \%$ overall.

It is sometimes difficult to be certain that all stones have been cleared, particularly in patients with dilated ducts. Those groups who do not attempt to extract all stones at the time of sphincterotomy (believing that most will pass spontaneously) cannot quote technical success rates, as not all patients are checked later. It should also be appreciated that the quoted figures only concern patients in whom an attempt at stone extraction is made. They exclude patients who are found to have duct stones at ERCP, but in whom a decision is made not to attempt endoscopic extraction because technical difficulties are predicted (for example very large stones). Local endoscopic success rates will appear to rise if these difficult patients are selected out and sent for surgery, or to another endoscopist.

In some patients sphincterotomy is difficult to achieve when the papilla is within a large diverticulum and it is a tour de force after Billroth II partial gastrectomy. ${ }^{10}$ Failure to extract stones may occur when sphincterotomy is followed by an immediate complication (such as bleeding, or perforation), but is most often because of the stone(s) being too large. Stones less than $1 \mathrm{~cm}$ in diameter can virtually always be removed, but there is increasing difficulty with those over $15-20 \mathrm{~mm}$. Results are not predictable; all endoscopists have seen very large stones pass spontaneously. For experts, the large stone is the last frontier. Perfusion of chemical agents through naso-biliary tubes have rarely been effective and these problems are now being tackled with improved crushing baskets. The size and shape of the duct itself also affects the result. Stones are more difficult to extract from large and tortuous ducts, from smaller ducts in which the stones fill the entire lumen and when there is relative narrowing below the stone: stones above true strictures cannot be removed intact.

Individual expertise is an obvious determinant of success; we have shown that results are poor during the learning phase. ${ }^{9}$ This is not surprising but, paradoxically, success rates may not be highest in those centres with the largest experience. Many difficult patients (such as failures from elsewhere) are referred, and initial attempts are often made by trainees.

Personal dexterity is only a part of expertise. Adequate equipment, facilities and trained assistants are essential. Some endoscopic procedures are presently being done under circumstances which would have been condemned in an operating theatre half a century ago.

SUCCESS RATES FOR SURGICAL TREATMENT

Which factors influence the success rates for surgical extraction of stones? Results are usually published in reverse - that is, as the proportion of failures, or of retained stones. Casual readers of the literature may find figures of less than $2 \%$, but these usually refer to all biliary operations. Retained stones are almost always confined to patients who have 
undergone positive duct exploration. ${ }^{11}$ Glenn ${ }^{12}$ found an average figure of $4.3 \%$ in this context, but figures of $10 \%$ and higher are recorded. ${ }^{13} 14$ Recent experience is better, particularly with the use of choledochoscopy, but even then the failure rate may be as high as $6 \%{ }^{15}$ or $8.9 \%{ }^{16}$ in respected centres. These figures must be compared with the success rates for endoscopic stone extraction (about 90\%) after sphincterotomy has been achieved, as there are occasionally operations at which the bile duct cannot be reached, or fully explored with safety - the equivalent of a failed sphincterotomy. Indeed, increasingly some surgeons do not prolong a difficult duct exploration, but simply place a large T-tube drain, knowing that alternative methods of clearance are available.

Published success rates are also influenced by the method of assessment and length of follow up. Surgical data usually refer to the results of early post operative T-tube cholangiography; this diagnostic method is not foolproof and excludes those patients who do not have a duct exploration and those in whom the duct is closed without a T-tube drain.

Although endoscopic sphincterotomy is being used increasingly in patients who have not undergone biliary surgery (in the elderly, frail and septic), most are still done for treatment of retained, or recurrent stones after cholecystectomy. As these patients are already failures of surgery, the results of endoscopic treatment should really be compared with those of a second, or a third operative procedure. Girard and Legros ${ }^{17}$ report a $2.9 \%$ recurrent stone rate in this context, but other data are less encouraging. Kune $^{11}$ quotes figures of 15 and $20 \%$ for second and third explorations. Allen and colleagues reported a $33 \%$ incidence of recurrent, or residual bile duct stones after secondary duct exploration (without biliary drainage) and no less than $83 \%$ (five of six) at a third or subsequent operation. ${ }^{18}$ These facts have encouraged the trend towards a biliary drainage procedure (such as choledochoduodenostomy) at re-operation, at least in patients with large ducts and many stones. ${ }^{18-21}$ If this advice is generally accepted, it is the results of biliary drainage which must be compared with endoscopic treatment in this context. Surgeons performing a choledochoduodenostomy may not always attempt to remove all the stones. Most of the excellent papers on this subject concentrate on short term morbidity, and on the long term benefits which will be discussed later.

It should be emphasised that repeat operations are likely to be more difficult than primary procedures and may fail for the same reason (such as difficult access due to obesity, or adhesions). Re-operations are more likely to be done by more experienced surgeons, but the influence of technical expertise has not been documented. If specialist biliary surgeons do have better results than general surgeons, it is probably because of their skills and team expertise - but the referral pattern makes comparisons difficult. Referral to a specialist centre may occur because a difficult procedure is contemplated, but this referred group will also include many sophisticated and relatively young patients; the acutely ill must be treated locally.

\section{Short term complications and predictive factors}

ENDOSCOPY

Published complication rates are remarkably consistent. ${ }^{3-9}$ Immediate problems (bleeding, pancreatitis, cholangitis and retro-peritoneal 
perforation) occur in 8-10\% of patients; surgery is needed urgently in $1-2 \%$ and the overall mortality is around $1 \%$.

These figures are not directly comparable with surgical data, for two reasons. Most early reports exclude non-endoscopic complications and deaths from 'incidental' problems such as myocardial infarction. They did include the risks of surgery done for endoscopic complications, but not usually for failed endoscopic treatment. A prospective multicentre British study $^{22}$ has taken these points into account. So far there have been 80 complications in 721 sphincterotomies $(11 \%)$, and nine deaths $(1 \cdot 2 \%)$; two of these were caused by cardio-pulmonary problems.

The second reason why these figures are difficult to compare with surgical data is much more important - the spectra of patients are very different. Unfortunately few endoscopic or surgical series provide a detailed breakdown, but it is obvious that patients referred for endoscopic treatment are generally older and sicker. The most striking data come recently from Carr-Locke. ${ }^{23}$ His group reported one death (in an elderly patient with a huge stone who presented in extremis) after endoscopic treatment of 59 patients who were judged to be unsuitable for surgery; $90 \%$ of the patients were jaundiced, $32 \%$ had cholangitis, and the mean age was 78 years.

Analysis of the complications does not indicate clear predictive factors. Greater risk might be expected in patients with acute biliary disease (jaundice, cholangitis, and pancreatitis), but data so far do not confirm this. ${ }^{24-27}$

At present there is no clear evidence that the risks of endoscopic treatment increase with age, or that they are influenced by previous biliary surgery. Larger sphincterotomies done for large stones are probably more dangerous and the risk of bleeding appears to be greater when a sphincterotomy is enlarged within a week or so. Surprisingly, there is no increased risk in patients with large diverticula, but there may be more complications (particularly retro-peritoneal perforation) when sphincterotomy is done for 'papillary stenosis'. This may be because the fibrosis present in patients with stones is lacking. Sphincterotomy is probably more hazardous in patients with portal hypertension and abnormalities of coagulation, but few such cases have been reported. Cholecystitis and empyema can occur within days of sphincterotomy when performed for patients with their gall bladders in place. ${ }^{23} 28$ This complication is very rare when antibiotics are given prophylactically.

\section{SURGERY}

There are many reports and reviews dealing with the hazards of biliary surgery and excellent studies of specific risk factors. ${ }^{26} 29-31$ Overall mortality figures are relatively unhelpful, for (apparently unlike endoscopic treatment), the risks are almost entirely dependent upon the patient's state of health, both acute and chronic. The mortality rate for common bile duct exploration in relatively fit patients under the age of 60 is less than $1 \% .{ }^{26} 32{ }^{33}$ Increasing age brings many general medical problems (such as diabetes, malnutrition, cardio-respiratory and renal insufficiency) with which the figures rise to more than $5 \% ;^{32}{ }^{34}$ some as high as $12.3 \%{ }^{35}$ or $28 \% .{ }^{36}$ Such global figures are also of little help, as the series are not comparable; they include different proportions of acute biliary problems in 
groups of patients with a variety of general medical disabilities. Some series do not separate elective operations (which can be performed relatively safely in the elderly) ${ }^{37} 38$ from emergency procedures which are hazardous at any age. For instance, two respected American surgical groups recently reported operative mortalities of $14 \%$ and $12 \%$ in relatively young patients with acute cholangitis. ${ }^{39}{ }^{40}$ Cirrhosis is another formidable risk factor which is independent of age. ${ }^{41} 42$

Emergency surgery is more dangerous than elective operation, but several factors are involved. Some patients may come to emergency operation when treatment has been postponed because of major medical disability ${ }^{43}$ furthermore, urgent procedures are more likely to be performed by trainees.

The risks of second operations on the common duct are less well documented. Most reports refer to elective procedures, with encouraging results. McSherry and Glenn ${ }^{26}$ reported a mortality of only $2.1 \%$ in 341 patients undergoing re-exploration of the duct. Girard and Legros ${ }^{17}$ had no deaths during re-operation in 72 patients (mean age 57 years). Lygidakis reported 45 re-explorations (with choledochoduodenostomy) without any mortality, but there were two deaths among 45 other patients undergoing re-operation without biliary drainage. ${ }^{44}$

\section{Long term results}

The choice of treatment for duct stones in elderly and frail patients is determined by short term results, because life expectancy is relatively short. All the evidence supports the use of endoscopic treatment rather than surgery in this context. The situation is different in younger and fit patients. Initial success rates and risks of endoscopic and surgical treatment are not dissimilar. The choice will be influenced substantially by the long term results, in particular the incidence of recurrent stones and cholangitis.

FOLLOW UP AFTER ENDOSCOPIC SPHINCTEROTOMY (POST

CHOLECYSTECTOMY)

Long term questions can only be answered in the long term, which must mean more than 10 years. It is evident from surgery that problems may increase progressively with the length of follow up. ${ }^{44}$ Relatively few patients have been followed for more than five years after endoscopic treatment. Most studies, including that from Toulouse reported in this issue of $\mathrm{Gut}^{8}{ }^{8}$ cover ranges of one to seven years. ${ }^{45-50}$ Results appear broadly consistent; about $10 \%$ of patients have major symptoms and of these $4.4 \%$ to $9.8 \%$ develop stenosis, new stones, or both. Most of these complications have been treated endoscopically.

We have followed 148 patients after endoscopic duct clearance. Six (4\%) developed serious biliary problems after one to six years ${ }^{49}$ (mean 31 months). One year later, the number had risen to $10(7.5 \%)^{50}$ - a mixture of stenosis alone, stenosis with stones, and stones without stenosis. The number of patients is too small to analyse for predictive factors, but it is interesting that many of these patients are already failures of second operations. Five of our 10 patients with recurrent problems had previously had two or more duct explorations. One has had the duct cleared so far four times surgically and three times endoscopically; at present he is well 
on drug treatment. Only one of these patients had undergone further surgery.

About two thirds of patients studied by ourselves ${ }^{50}$ and the Toulouse group $^{8}$ had air in the biliary tree and free reflux of barium up the bile duct. Virtually all of the 36 patients which we submitted to repeat endoscopy had bacterial overgrowth in the bile, whether or not they had any symptoms ${ }^{5(1}$; counts were higher in old patients with large ducts. The significance of these findings is unknown.

Most of the patients followed up for longest are elderly (as they were the only ones offered endoscopic treatment initially). This is important for two reasons. Detailed follow up studies are difficult to do in such patients and most reports are based mainly on questionnaires. It is not often justifiable to re-investigate those who are asymptomatic - some of whom might also have stones. The second problem is that observations made in the elderly may not reflect those in young patients, and it is those which are really needed for comparison. It may be that persistence of biliary bacteria and the development of pigment stones is influenced by achlorhydria in some elderly patients.

Endoscopic sphincterotomy could possibly lead to distant complications in the liver, pancreas, stomach, or colon by effects on bile salt turnover; no such hazards have yet been recognised after endoscopic or surgical treatment.

FOLLOW UP AFTER SURGICAL DUCT EXPLORATION

Considering the huge volume of biliary surgery, there are surprisingly few studies of long term follow up after surgical exploration of the duct, particularly recently. Bordley and White ${ }^{51}$ suggest that 'at least 3-10\% of patients can expect to undergo at least one further procedure on the biliary tract', but such figures refer to the whole range of operations. A five year follow up of 208 patients who underwent cholecystectomy and duct exploration at the Mayo clinic in 1957-58 revealed 5.3\% with recurrent biliary problems. ${ }^{52}$ Peel reported a $10 \%$ incidence of complications in periods of up to 12 years. ${ }^{53}$ Six to eight year follow up of 190 patients by White and Bordley showed only three with problems. ${ }^{54}$ Follow up studies after transduodenal duct exploration have documented problems in up to $3 \%$ of patients. ${ }^{55-57}$ For comparison with endoscopic data, we need to know the long term results of re-exploration of the duct. Recurrent stone rates as disparate as $2.9 \%$ and $83 \%$ have been quoted already in the section on success rates. ${ }^{18}$ High recurrence rates have led many to advocate a biliary drainage procedure when re-operating, particularly in patients with large ducts and many stones. Degenshein reported only $1.3 \%$ of recurrent problems after choledochoduodenostomy, with a follow up extending to 18 years. ${ }^{21}$ The most striking results are reported by Lygidakis; ${ }^{44} 90$ patients with recurrent stones were randomised to treatment by duct exploration alone, or by choledochoduodenostomy, and were followed for $6-11$ years. Those treated by duct re-exploration alone had a $20.9 \%$ rate of further operation, whereas none of those undergoing choledochoduodenostomy needed further surgery. Results almost as impressive are reported by Moesgaard et al. ${ }^{58}$ from Denmark, and by Stuart and Hoerr. ${ }^{59}$

Bacteria are present in the bile in most patients with stones; they can 
persist after surgical exploration ${ }^{(0)}$ as after endoscopic sphincterotomy, and late cholangitis can occur despite apparently adequate drainage. ${ }^{61}$

FOLLOW UP AFTER ENDOSCOPIC SPHINCTEROTOMY IN PATIENTS WITH

GALL BLADDERS IN SITU

Nowadays, about half of all patients undergoing sphincterotomy for duct stones in major units have not previously undergone any biliary surgery. There are two reasons which often overlap. Patients with acute biliary disease (jaundice, cholangitis, gall stones pancreatitis) can be treated initially with endoscopic duct decompression, and come to cholecystectomy electively in reasonable condition. The second group of patients are the elderly and frail, whose chronic symptoms settle completely after endoscopic clearance of the duct. What are the indications for cholecystectomy, when life expectancy is short? Follow up of those patients who have left hospital without cholecystectomy is particularly interesting. We found that only $10 \%$ of 260 such patients (mean age 76 years) required cholecystectomy for biliary pain or cholecystitis during a follow up of $1-6$ years. ${ }^{62}$ In this issue of Gut Escourrou and colleagues report similar figures; follow up of 130 patients at six to 66 months revealed late cholecystitis in only eight $(6 \%)$ and other biliary problems in a similar number. ${ }^{8}$ In both series virtually all the patients coming to cholecystectomy needed it within one year. Shorter follow up of 59 patients by Carr-Locke's group ${ }^{23}$ showed equally encouraging results; 16 patients died between four and 50 months, but only one from gall bladder disease. Not surprisingly, these figures appear to lie between those reported for the follow up of asymptomatic ${ }^{6.3}$ and symptomatic ${ }^{3.3}$ gall bladder stones.

Predictive factors for further trouble are still being analysed, but it appears that a blocked cystic duct may be important. Some patients have empty gall bladders at the time of endoscopic sphincterotomy and many others pass their stones subsequently. One patient is known to have developed gall bladder cancer four years after sphincterotomy. ${ }^{8}$

COSTS AND DISCOMFORT

Endoscopic treatment is preferred by patients (when it succeeds) and is substantially cheaper than surgery. Most procedures can be completed within 30 minutes, but some take longer and about $20 \%$ of patients need two or more endoscopies. The mean operating time for duct exploration at the Massachusetts General Hospital is 2.8 hours $(3.6$ hours with choledochoscopy). ${ }^{16}$ Most patients undergoing endoscopic treatment are discharged from hospital within six days (often within two days), whereas surgical treatment usually takes substantially longer, especially in the elderly and frail. ${ }^{64}$ Real comparisons would require totalling the costs (both financial and personal) over decades, as long term sequelae should be included.

\section{Future developments}

The future role of endoscopic treatment will be influenced by technical developments. The only real drawback is the sphincterotomy itself, as this is the main cause of complications. Recently it has been shown that some small stones can be extracted endoscopically without a sphincterotomy, ${ }^{65}$ 
by dilating the papilla with an angioplasty-type balloon; effective crushing baskets should make this method suitable for larger stones. ${ }^{66}$ Another technique for removing stones without sphincterotomy is to dissolve them in situ. Chemicals can be perfused through endoscopically placed nasobiliary catheters; results with agents which are currently available are disappointing. ${ }^{67}$ The development of new chemicals, or better, of drugs which are rapidly effective when given orally, would have a major impact, and inevitably replace much invasive treatment. ${ }^{68}$

\section{Conclusion}

The Table is a personal attempt to list and weight the factors which now influence the choice of treatment; it is presented to provoke discussion, and to promote the studies which are needed to define the real factors, and their individual importance. Long term results are not included, as comparable data are not yet available.

It is already clear that endoscopic sphincterotomy is a major advance in the treatment of many elderly and high risk patients with duct stones. It should replace surgery in most such patients with retained or recurrent stones, and appears justified in many patients who have not yet undergone cholecystectomy - either in the hope of avoiding biliary surgery altogether, or to defuse an acute clinical situation. Despite reservations by some surgeons, ${ }^{26} 27$ most experienced endoscopists have excellent results in the emergency management of patients with jaundice and acute cholangitis. The role of endoscopic treatment in the young and fit has yet to be established, but many such patients are now being referred, usually by surgeons.

Biliary surgery is the commonest type of abdominal operation performed in Britain. The development and acceptance of endoscopic treatment (as in other fields) has major implications for surgical training and practice. If endoscopic treatment becomes more widely used, the

Table A personal view of the factors (and their weight) which currently influence the choice between endoscopic treatment (plus scores) and surgical treatment (minus scores) for common bile duct stones

\begin{tabular}{llc}
\hline Age & for each decade over 50 & +1 \\
General health problems & minor & +1 \\
& moderate & +2 \\
& severc & +3 \\
Acute biliary illness & jaundice & +1 \\
& cholangitis & +2 \\
Gall bladder status & no previous cholecystectomy & -3 \\
Access & Billroth II gastrectomy & -3 \\
& previous difficult biliary surgery & +2 \\
& previous very difficult biliary surgery & +3 \\
Expertise & obesity; wt $>20 \%$ above ideal & +1 \\
& sphincterotomy experience $>100$ & +1 \\
Problems for endoscopy & specialist biliary surgeon & -1 \\
(when data available) & stone above stricture & -1 \\
& tortuous dilated duct & -3 \\
& stone size $15-20 \mathrm{~mm}$ & -1 \\
\hline
\end{tabular}


breadth of surgical experience will gradually decrease, especially in the high risk context. Perhaps it is time to realise that the endoscopic techniques are simply a new way of performing surgery, and to re-arrange the structures of specialisation.

Department of Gastroenterology

P B COTTON

The Middlesex Hospital

London

\section{References}

1 Classen M, Demling L. EPT - 10 years on. Proceedings International conference Erlangen 1983. Stuttgart: Georg Thieme 1984. (In press.)

2 Tweedle DEF, Martin DF. Choledocho-lithiasis - surgical or endoscopic lithotomy. [Abstract] Gut 1981; 22: A888.

3 Siegel JH. Endoscopic papillotomy in the treatment of biliary tract disease; 258 procedures and results. Dig Dis Sci 1981; 26: 1057-1064.

4 Safrany L. Endoscopic treatment of biliary tract disease. Lancet 1978; 2: 983-5.

5 Koch H, Rosch W, Schaffner O, et al. Endoscopic papillotomy. Gastroenterology 1977; 73: 1393-6.

6 Geenen JE, Vennes JA, Silvis SE. Resume of a seminar on endoscopic retrograde sphincterotomy (ERS). Gastrointest Endosc 1981; 27: 31-8.

7 Reiter JJ, Bayer HB, Mennicken C, Manegold PC. Results of endoscopic papillotomy; a collective experience from 9 endoscopic centres in West Germany. World J Surg 1978; 2: 505-7.

8 Escourrou J, Cordova JA, Lazorthes F et al. Early and late complications after endoscopic sphincterotomy for biliary lithiasis, with and without the gallbladder 'in situ'. Gut 1984; 25: $598-602$.

9 Cotton PB, Vallon AG. British experience with duodenoscopic sphincterotomy for removal of bile duct stones. Br J Surg 1981; 68: 373-5.

10 Safrany L, Neuhaus B, Porto-Carrero G, Krause S. Endoscopic sphincterotomy in patients with Billroth II gastrectomy. Endoscopy 1980; 12: 16-22.

11 Kune GA. Current proceedings of biliary surgery. Boston: Little Brown, 1972. 221-3.

12 Glenn F. Retained calculi within the biliary ductal system. Ann Surg 1974; 179: 528-39.

13 Way LW, Admirand WH, Dunphy JE. Management of choledocholithiasis. Ann Surg 1972; 176: 347-59.

14 Kappes SK, Adams MB, Wilson SD. Intra-operative biliary endoscopy: mandatory for all common duct operations? Arch Surg 1982; 117: 604-7.

15 Feliciano DW, Mattox KL, Jordan GL. The value of choledochoscopy in exploration of the common bile duct. Ann Surg 1980; 191: 649-53.

16 Rattner DW, Warshaw AL. Impact of choledochoscopy on the management of choledocho-lithiasis. Ann Surg 1981; 194: 76-9.

17 Girard RM, Legros G. Retained and recurrent bile duct stones. Surgical or non-surgical removal. Ann Surg 1981; 193: 150-4.

18 Allen B, Shapiro H, Way LW. Management of recurrent and residual common duct stones. Am J Surg 1981; 142: 41-47.

19 Lygidakis NJ. Choledocho-duodenostomy in calculus biliary tract disease. Br J Surg 1981; 68: 762-5.

20 Degenshein GA. Choledocho-duodenostomy; an 18 year study of 175 consecutive cases. Surgery 1974; 76: 316-24.

21 Madden JL, Chun JY, Kandalaft S, Parekh M. Choledocho-duodenostomy. An unjustly maligned surgical procedure? Am J Surg 1970; 119: 425-54.

22 Frost RA. A prospective multi-centre computer based study of British ERCP and sphincterotomy. [Abstract] Gut 1984; (in press).

23 Neoptolemos JP, Carr-Locke DL, Fraser I, Fossard DP. The management of common bile duct calculi by endoscopic sphincterotomy in patients with gallbladders in situ. $\mathrm{Br} \mathrm{J}$ Surg 1984; 71: 69-71. 
24 Vallon AG, Shorvon PJ, Cotton PB. Duodenoscopic treatment of acute cholangitis. [Abstract] Gut 1982; 23: A915.

25 Safrany L, Cotton PB. A preliminary report. Urgent duodenoscopic sphincterotomy for acute gallstone pancreatitis. Surgery 1981; 89: 424-8.

26 McSherry CK, Glenn F. The incidence and causes of death following surgery for non-malignant biliary tract disease. Ann Surg 1980: 191; 271-5.

27 Chock E, Wolfe BM, Matolo NM. Acute suppurative cholangitis. Surg Clin N Am 1981; 61: 885-92.

28 Cotton PB, Vallon AG. Duodenoscopic sphincterotomy for removal of bile duct stones in patients with gallbladders. Surgery 1982; 91: 628-30.

29 Pitt HA, Cameron JL, Postier RG, Gadacz TR. Factors affecting mortality in biliary tract surgery. Am J Surg 1981: 141: 66-72.

30 Blamey SL, Fearon KCH, Gilmore WH, Osborn DH, Carter DC. Prediction of risk in biliary surgery. Br J Surg 1983; 70: 535-8.

31 Dixon JM, Armstrong CB, Duffy SW, Davies GC. Factors affecting morbidity and mortality after surgery for obstructive jaundice; a review of 373 patients. Gut 1983; 24: 845-52.

32 Glenn F. Trends in surgical treatment of calculus disease of the biliary tract. Surg Gynecol Obstet 1975; 140: 877-84.

33 Wenckert A, Robertson B. The natural course of gallstone disease. 11 year review 781 non-operated cases. Gastroenterology 1966; 50: 376-81.

34 Doyle PJ, Ward-McQuaid JN, McEwen-Smith A. The value of routine pre-operative cholangiography - a report of 4000 cholecystectomies. Br J Surg 1982; 69: 617-9.

35 Spohn K, Fux HD, Mehnert U, Muller-Kluge M, Tewes G. Cholecystektomie und choledochotomie - Taktik und Techniken. Langenbecks Arch Chir 1973; 334: 249-54.

36 Vellacott KD, Powell PH. Exploration of the common bile duct; a comparative study. $\mathrm{Br} J$ Surg 1979; 66: 389-91.

37 Sullivan DM, Ruffin-Hood T, Griffen WO. Biliary tract surgery in the elderly. Am J Surg 1982; 143: 218-20.

38 Houghton PJW, Donaldson LA. Elective biliary surgery - a safe procedure. Geriatr Med 1983; 13: 814-6.

39 Thompson JE, Tompkins RK, Longmire WP. Factors in management of acute cholangitis. Ann Surg 1982; 195: 137-45.

40 Boey JH, Way LW. Acute cholangitis. Ann Surg 1980; 190: 264-70.

41 Schwartz SI. Biliary tract surgery and cirrhosis; a critical combination. Surgery 1981; 90: 577-83.

42 Aranha GV, Sontag SJ, Greenlee HB. Cholecystectomy in cirrhotic patients; a formidable operation. Am J Surg 1982; 143: 55-60.

43 Gaines RD. Surgery for gallbladder disease in the elderly. Geriatrics 1977; 36: 71-4.

44 Lygidakis NJ. Surgical approaches to recurrent choledocho-lithiasis. Am J Surg 1983; 145: 633-9.

45 Seifert E, Gail K, Weismuller J. Langzeitresultate nach endoskopischer sphinkterotomie, follow-up studie aus 25 centren in der Bundesrepublik. Dtsch Med Wochenschr 1982; 107: 610-4.

46 Rosch W, Riemann JF, Lux G, Lindner HG. Long term follow-up after endoscopic sphincterotomy. Endoscopy 1981; 13: 152-3.

47 Brandstatter G von, Kratochvil P, Stupnicki Th, Justich E, Kopp W. Langzeitergebnisse nach endoskopischer papillotomie. Fortschr Med 1983; 101: 1237-40.

48 Safrany L, Schott B, Balint T. Endoscopic sphincterotomy: The long term results in choledocholithiasis. [Abstract] Gastrointest Endosc 1982; 28: 152.

49 Vallon AG, Cotton PB, Holton J. Clinical and endoscopic follow-up after duodenoscopic sphincterotomy. [Abstract] Gut 1982; 22: A889.

50 Vallon AG, Holton JM, Cotton PB. Follow-up after duodenoscopic sphincterotomy for recurrent duct stones. Br J Surg 1984 (In press).

51 Bordley J, White TT. Causes for 340 re-operations on the extra-hepatic bile ducts. Ann Surg 1979; 189: 442-6.

52 Larson RE, Hodgson JR, Priestley JT. The early and long term results of 500 consecutive explorations of the common duct. Surg Gynaecol Obstetrics 1966; 122: 744-50.

53 Peel ALG, Bourke JB, Hermon Taylor J, et al. How should the common bile duct be explored? Ann $R$ Coll Surg 1975; 56: 124-34.

54 White TT, Bordley J. One percent incidence of recurrent gall stones six to eight years after manometric cholangiography. Ann Surg 1978; 188: 562-9. 
55 Thomas CG, Nicholson CP, Owen J. Effectiveness of choledochoduodenostomy and transduodenal sphincterotomy in the treatment of benign obstruction of the bile duct. Ann Surg 1971; 173: 845-56.

56 Stefanini P, Carboni M, Patrassi N et al. Transduodenal sphincteroplasty: its use in the treatment of lithiasis and benign obstruction of the common duct. Am J Surg 1974; 128: 672-7.

57 Jones SA. The prevention and treatment of recurrent bile duct stones by transduodenal sphincteroplasty. World J Surg 1978; 2: 473-85.

58 Moesgaard F, Nielsen ML, Pedersen T, Hansen JB. Protective choledochoduodenostomy in multiple common duct stones in the aged. Surg Gynecol Obstet 1982; 154: 232-4.

59 Stuart M, Hoerr SO. Late results of side to side choledocho-duodenostomy and of trans-duodenal sphincterotomy for benign disorders. Am J Surg 1972; 123: 67-72.

60 Silen W, Wertheimer M, Kirshenbaum G. Bacterial contamination of the biliary tree after choledochostomy. Am J Surg 1978; 135: 325-7.

61 Goldman LD, Steer ML, Silen W. Recurrent cholangitis after biliary surgery. Am J Surg 1983; 145: 450-4.

62 Safrany L, Cotton PB. Endoscopic management of choledocholithiasis. Surg Clin N Am 1982; 62: 825-36.

63 Gracie WA, Ransohoff DF. The natural history of silent gall stones, the innocent stone is not a myth. $N$ Engl J Med 1982; 307: 798-800.

64 Cotton PB. Therapeutic endoscopy; gallstones and pancreatitis. In: Sarner M, ed, Advanced medicine 18. London: Pitman Medical, 1982.

65 Staritz M, Ewe K, Meyer Zum Buschenfeld KH. Endoscopic papillary dilatation, a possible alternative to endoscopic papillotomy. Lancet 1982; 1: 1306-7.

66 Riemann JF, Seuberth K, Demling L. Mechanical lithotripsy through the intact papilla of Vater. Endoscopy 1983; 15: 111-3.

67 Hoffman AF, Schmack B, Thistle JL, Babayan VK. Clinical experience with monooctanoin for dissolution of bile duct stones. Dig Dis Sci 1981; 26: 954.

68 Dowling H. Management of stones in the biliary tree. Gut 1983; 24: 599-608. 